\title{
PRIMEIRAS CRISES PSICÓTICAS: IDENTIFICAÇÃO DE PRÓDROMOS POR PACIENTES E FAMILIARES
}

\author{
Nerícia Regina de Carvalho* \\ Ileno Izidio da Costa**
}

\section{RESUMO}

Este artigo é resultado de uma dissertação de mestrado que procurou caracterizar as crises psicóticas por meio da fala de pacientes e de seus familiares que passaram pelas suas primeiras crises, baseada na literatura e pesquisas recentes sobre intervenção precoce nas psicoses (McGorry \& Edwards, 2002), nos estudos sobre crise (DiTomasso \& Kovnat, 1995; Miermont e cols., 1994; Tavares, 2004) e sobre família (Addington e cols., 2005). Os dados obtidos foram trabalhados de acordo com a análise de conteúdo (Bardin, 1988; Franco, 2003). Constatou-se que as crises psicóticas, embora questionáveis do ponto de vista diagnóstico, se manifestaram conforme a literatura corrente (CID-10, 1993; McGorry $\&$ Edwards, 2002). Ansiedade, medo, isolamento social e desconfiança foram os pródromos identificados, e alucinação e delírio, os sintomas recorrentes.

Palavras-chave: crise psicótica; pródromos; intervenção precoce; família

\section{AbSTRaCT \\ FIRST PSYCHOTIC CRISIS: PRODROMS IDENTIFICATION BY PATIENTS AND FAMILY MEMBERS}

This article is the result of a master's degree thesis which tried to characterize psychotic crisis by the account of patients and family members in their first crisis. The study was based on

* Psicóloga (Universidade Federal do Maranhão); Especialista em Bioética; Mestre em Psicologia (Universidade de Brasília); Membro do GIPSI - Grupo de Intervenção Precoce nas Psicoses do Departamento de Psicologia Clínica e Cultura da Universidade de Brasília (UnB).

** Professor Adjunto do Departamento de Psicopatologia Clínica da Universidade de Brasília (UnB); Mestre em Filosofia e Ética da Saúde Mental (Warwick/Inglaterra); Doutor em Psicologia Clínica (UnB/Warwick); Coordenador da Clínica Escola e do Grupo de Intervenção Precoce nas Psicoses (GIPSI) do Instituto de Psicologia Clínica e Cultura da Universidade de Brasília (UnB). 
recent literature, surveys regarding early intervention in psychosis (McGorry \& Edwards, 2002), studies about crisis (DiTomasso \& Kovnat, 1995; Miermont e cols., 1994; Tavares, 2004) and about family (Addington et al., 2005). The data obtained was processed through Content Analysis (Bardin, 1988; Franco, 2003). It was noted that psychotic crisis were manifested according to literature states (CID-10, 1993; McGorry \& Edwards, 2002). Anxiety, social isolation, fear and suspicion were the identified prodroms, and hallucination and delirium, the related symptoms.

Keywords: psychotic crisis; prodroms; early intervention, family

Ao longo da vida passamos por momentos de conflito e desequilíbrio. A essas situaçôes, geralmente sinalizadas por fatores biopsicossociais, denominamos crise. Quando de seu surgimento, o sujeito pode vivenciar graus variados de estresse (respostas subjetivas) e suas conseqüências dependem da situação, do sujeito (recursos pessoais) e de sua interação com o meio (Tavares, 2004). Porém, apesar de o termo ser amplamente utilizado, por vezes referindo-se a situações críticas, nem sempre seu uso se faz adequado. Etapas do ciclo de vida que são potencialmente geradoras de crise, como adolescência, casamento, separação, desemprego, etc, não levam, obrigatoriamente, o sujeito à crise (Hegenberg, 1996).

Dentro do contexto familiar, a crise corresponderia a um período de tensão e de conflito que aparece periodicamente e que pode ser produzido tanto por uma mudança vivida pela família quanto como conseqüência de uma intervenção terapêutica. Toda crise provoca uma ruptura temporária da homeostase do sistema familiar e, por conseguinte, uma necessidade de reorganização das inter-relaçôes e uma descoberta de novas regras de funcionamento familiar. A crise habitualmente surge durante as mudanças impostas pelos ciclos da vida familiar (Miermont, 1994). Nesse contexto, o sintoma pode ser sinal de perturbação pertencente à família e não simplesmente ao indivíduo, indicando problemas em negociar as transições dos ciclos de vida (Carter \& McGoldrick, 1995).

$\mathrm{O}$ contexto de crise priorizado neste trabalho é aquele cujo aparecimento causa desequilíbrio psíquico, no qual o sujeito se encontra desprovido das competências que o levam a uma re-acomodação às situações de conflito.

DiTomasso e Kovnat (1995) definiram crise como uma experiência durante a qual o indivíduo enfrenta um agente de estresse considerado intransponível, mesmo com o uso de abordagens características para a resolução de problemas. Desse modo, podemos então considerar que as crises são aqueles acontecimentos da vida que atacam e ameaçam o senso de segurança e controle da pessoa. Em se tratando de esquizofrenia, por exemplo, a crise geralmente significa fase aguda em 
que se tornam perceptíveis os sintomas positivos (alucinações e delírios) do paciente - em situação de primeira crise psicótica; ou, ainda, ocasião em que tais sintomas surgem ou se exacerbam - recaídas e recidivas (Leff, Kupers, Bertowitz \& Strugeon, 1985).

Ainda que a crise, em especial aquelas do tipo psicótica, pareça se manifestar de forma aleatória e abrupta, há um momento, anterior à sua eclosão, em que é possível observar algumas alterações sutis na vivência do sujeito. Esse período, denominado pródromos, se caracteriza por sinais como: isolamento social, deterioração do funcionamento social, comportamento estranho, deterioração do trato pessoal e higiene, embotamento afetivo ou afeto inapropriado, alteração do discurso, crenças e pensamentos mágicos, percepção incomum das experiências e falta de iniciativa, interesse ou energia. Os pródromos constituem um período de transtorno não psicótico no comportamento ou na vivência do paciente, precedendo o surgimento da psicose, e, uma vez possíveis de serem reconhecidos, podese interromper a progressão da psicose ou facilitar o tratamento após seu surgimento (McGorry \& Edwards, 2002).

O fato de um sujeito apresentar sinais indicadores de pródromos não quer dizer, necessariamente, que essa fase progredirá para uma crise psicótica ou para um adoecimento mental, mas sim que estes sinais constituem "um estado mental de risco" (Eaton, Badawi \& Melton, 1995; McGorry \& Singh, 1995).

O termo "psicose" sempre foi utilizado em diferentes sentidos e em diversas situações. As definições em psiquiatria são muitas e não há nenhuma plenamente satisfatória, pois a psicose não se refere a uma doença específica, tal como nos aponta Costa (2003). Contudo, de forma mais simples e direta, pode-se considerar que a psicose se diferencia por alteraçôes psicológicas graves e muito mais comprometedoras que outros distúrbios, como é o caso da neurose.

Em seu texto "A perda da realidade na neurose e na psicose", Freud ([1924] 1976) afirma que a diferença que existe entre elas "é o fato de que em uma neurose o ego, em sua dependência da realidade, suprime um fragmento do id (da vida pulsional), ao passo que, em uma psicose esse ego, a serviço do id, se afasta de um fragmento da realidade" (Freud, [1924] 1976: 229).

Não podemos ainda oferecer uma definição pronta do que seja uma crise psicótica propriamente dita, uma vez que pretendemos problematizá-la através da pesquisa aqui apresentada. Porém esta caracterização obedece ainda à sintomatologia clássica (delírio e alucinação), como se observa nos manuais de classificação dos transtornos mentais.

A CID-10 (1993), por exemplo, descreve a manifestação da psicose como uma alteração significativa na qualidade global do comportamento pessoal, perda 
de interesse, retração social, além dos sintomas abaixo, por pelo menos um mês: alteração das funções mais básicas que dão à pessoa senso de individualidade, unicidade e de direção de si mesmo; eco, inserção e irradiação ou roubo de pensamento; delírios de influência, controle e passividade; vozes que comentam a ação; delírios persistentes culturalmente inapropriados; alucinações persistentes de qualquer modalidade, sem claro conteúdo afetivo; interceptação ou bloqueio de pensamento; comportamento catatônico, com flexibilidade cerácea, negativismo, mutismo etc; sintomas negativos (empobrecimento afetivo, autonegligência, diminuição da fluência verbal etc).

Nem todas as situaçôes em que são identificados pródromos evoluem para uma crise psicótica. Contudo, a maior parte dos casos de pródromos em psicose acaba por evoluir para uma esquizofrenia (Edwards, Maude, McGorry, Harrigton \& Cocks, 1998; Power, Elkis, Adlard, Curry, McGorry \& Harrington, 1998). Porém, no momento do primeiro episódio, o curso da doença é desconhecido e a psicose demanda tratamento imediato. A intervenção precoce na psicose, então, refere-se ao tratamento que enfatiza a importância do tempo e do tipo de prevenção oferecida às pessoas que se encontram em situação de primeiras crises (Lines, 2003).

Precoce quer dizer tão logo quanto possível, segundo o início dos sintomas psicóticos. Intervenção se refere à amplitude, intensidade, especificidade e individualização do tratamento, podendo ajudar a evitar a deterioração biológica, social e psicológica nos primeiros anos que se seguem ao início da psicose (Birchwood, 1992). Nesse sentido, a intervenção precoce diz respeito à presente orientação no campo de pesquisa e prática clínica com relação à psicose.

Costa (no prelo) propôs a intervenção precoce como ações terapêuticas imediatas, sejam medicamentosas, psicológicas ou relacionais, utilizadas o quanto antes para minimizar os "efeitos deletérios dos processos condicionantes" quando há altos níveis de angústia. $\mathrm{O}$ autor não restringe a intervenção precoce à psicose ou a qualquer classificação específica, priorizando o sofrimento humano em si.

Apesar das pesquisas apontarem que a família desempenha um importante papel no impacto causado pelo início da psicose em um de seus membros, o número de estudos continua inexpressivo (Burbach \& Stanbridge, 1998). O que se encontra na investigação dessas famílias são relatos de sofrimento, sobrecarga, ansiedade, depressão e aumento do ônus econômico (Addington, Colins, McCleery \& Addington, 2005; Barrowclough, Tarrier \& Johnston, 1996; Schene, van Wijngaarden \& Koeter, 1998; Schene, Tessler \& 
Gamache, 1994; Szmukler, 1996). Essas famílias também relatam maior grau de sofrimento em comparação com aquelas cujos membros já apresentam quadro de cronificação (Addington e cols., 2005; Martens \& Addington, 2001). Contudo, ainda é necessário maior investigação sobre a experiência dos familiares na situação de primeiros episódios.

O sofrimento experienciado decorre da incorporação do papel de cuidador aos papéis familiares já existentes. Há dois tipos de sofrimento: o objetivo - que envolve a disruptura dos deveres e obrigações familiares em razão do adoecimento e é facilmente observável - e o subjetivo - relativo às conseqüências psicológicas da situação para a família (Martens \& Addington, 2001). O apoio e as intervenções permanentes nas famílias, somados à assistência direta aos pacientes, podem reduzir as recaídas nos casos de psicose, o que resulta em maior ênfase ao trabalho com familiares de pacientes psicóticos (McGorry \& Edwards, 2002).

\section{Metodologia}

\section{OBJETIVOS}

Geral - caracterizar os episódios iniciais de psicose, identificando seu desenvolvimento.

Específicos - Identificar na perspectiva do paciente e de sua família:

$\rightarrow$ Indicadores prodrômicos da crise psicótica;

$\rightarrow$ Eventos que possam ter contribuído para o desencadeamento da crise;

$\rightarrow$ Modificações, na dinâmica familiar, decorrentes da crise;

$\rightarrow$ Estratégias utilizadas para lidar com a crise.

Participaram da pesquisa 5 (cinco) pacientes com diagnóstico entre F20-F29 (Esquizofrenia, Transtorno Esquizotípico e Delirante), segundo a CID-10, com histórico de intervenção psiquiátrica há no máximo 12 meses, em que tenham sido descartadas as seguintes hipóteses diagnósticas: uso de substâncias psicotrópicas em período próximo ao da crise; condição médica geral que aponte para outra causa à crise; paciente já identificado anteriormente por outro transtorno metal que não o já citado; paciente com histórico de crise anterior que tenha feito uso de medicamento antipsicótico ou neuroléptico de qualquer tipo. Participaram também 6 (seis) familiares desses pacientes. Todos assinaram Termo de Consentimento Livre-Esclarecido, sendo suas identidades preservadas pela adoção de nomes fictícios para quaisquer trabalhos e/ou publicações resultantes da pesquisa. 
O estudo foi realizado nos seguintes locais:

No Distrito Federal, no Hospital São Vicente de Paula (Taguatinga - DF), no CAEP (Centro de Atendimento e Estudos Psicológicos) do Instituto de Psicologia da UnB, por meio do GIPSI (Grupo de Intervenção Precoce nas Psicoses).

Em Goiânia, no CAPS (Centro de Atenção Psicossocial) Vida e Novo Mundo.

\section{Procedimentos}

Para coleta de dados da pesquisa foram utilizados dois roteiros de entrevista semi-estruturada elaborados para esse fim. O primeiro, utilizado com os pacientes, era composto de duas partes: 1a) Escala Breve de Avaliação Diagnóstica BPRS (Rhoades \& Overall, 1998), para identificar sinais e sintomas da crise, fatores socioeconômicos do paciente e o percurso clínico desde sua chegada ao serviço de saúde; $2^{a}$ ) Roteiro de entrevista semi-estruturada baseado na BPRS e nos objetivos do trabalho, para identificar as estratégias utilizadas na crise, os eventos envolvidos em seu desencadeamento e/ou manifestação e as mudanças decorrentes da situação. O segundo roteiro, utilizado com os familiares, baseavase na BPRS e nos objetivos do trabalho para identificar os mesmos aspectos.

Entre as razões para a escolha do instrumento destacam-se: facilidade de aplicação em diferentes condiçõos clínicas e de pesquisa; o fato de cobrir um amplo espectro de manifestaçôes psiquiátricas; base metodológica sólida, com inúmeros estudos de estrutura fatorial e de perfis classificatórios; possibilidade de comparação de resultados proporcionada pela sua ampla utilização (Bech, Malt \& Dencker, 1993).

Uma vez de posse de todas as entrevistas, os participantes receberam nomes fictícios.

A análise de conteúdo de Franco (2003), baseado em Bardin (1988), foi o método de análise de dados eleito. Foi utilizada a análise de categorias temáticas, na qual o tema é a unidade de significação que se depreende do texto analisado de acordo com critérios relativos à teoria que serve de guia (Minayo, 1994). Salientase que o critério de categorias temáticas submete os dados à apreciação exaustiva, a fim de conferir objetividade e pertinência à classificação, identificando qualitativamente os assuntos principais e os alvos de interesse dos entrevistados.

Esse método foi escolhido por comportar os aspectos qualitativos e quantitativos dos dados, sem detrimento destes últimos. Participaram da fase de levan- 
tamento de categorias gerais duas metodólogas. Contudo, as categorias finais, bem como os quadros demonstrativos, foram executados pelos autores. Esse método propicia encontrar marcadores e aspectos, gerais e particulares, às informaçōes obtidas.

\section{RESULTADOS E DISCUSSÃO}

\section{HISTÓRICO DO ADOECIMENTO}

Ao iniciar o relato sobre o início da crise psicótica, os entrevistados demarcaram um determinado evento ocorrido como um marco nas mudanças de comportamento observadas. As situações citadas foram de morte, traição, adoecimento, prisão, agressão e perigo de assalto, nas quais predominavam a sensação de desamparo, abandono e insegurança. Tais situações exigiram dos pacientes uma atitude diante da vida para a qual não dispunham de recursos, o que foi observada na disruptura emocional causada. As situações apresentaram-se desestruturantes por se darem de forma brusca e inesperada (morte, prisão, agressão), ou pela exposição constante e maciça do paciente a situaçóes de estresse e conflito (doença, perigo de assalto, suspeita de traição).

"Eu achava que meu irmão tava saindo com minha ex-mulher e tal. Entrei numa crise total, não aceitava aquilo." (Sandro)

Os pródromos, tal como discutido anteriormente, se considerados em sua etiologia, dizem respeito àquilo que antecede um evento. Nesse caso, seriam as situações identificadas como marcadores ao evento da própria crise psicótica (McGorry \& Edwards, 2002).

"Esses pensamentos de roubo, de polícia, eu tomei um medo de polícia, achando que ia ser presa." (Sara)

A sensação de medo é descrita por todos os pacientes. O medo aqui figura como pródromo principal, apesar de não ser destacado nos principais quadros de sinais de McGorry e Edwards (2002). No relato supracitado, o medo apareceu como pródromo que evoluiu para um sintoma. Enquanto pródromo, o medo não indica sofrimento psíquico grave, porém, num contexto de um delírio, aponta para uma sintomatologia clássica, bem como quaisquer outros pródromos com percurso sintomatológico semelhante. Para os autores supracitados, o medo aparece como obstáculo ao tratamento, referente ao estigma e à falta de conhecimento da doença. 
Todas as situações relatadas se referem a acontecimentos relacionados ao amadurecimento e ciclos de vida que podem ou não ocasionar uma crise. Esses fatos podem apontar para o não-preparo dessas pessoas para arcar com tais modificaçōes e reveses. A relação de causalidade estabelecida pode revelar a escassez de recursos criativos em se lidar com situaçóes novas.

\section{IDENTIFICAÇÃO DE UMA SITUAÇÃO CRÍTICA}

A identificação de uma situação crítica configura a identificação de fato de uma crise. É quando a escassez de recursos é tal que se faz necessária ajuda externa, ao indivíduo ou à própria família. Outra questão que sinalizou uma situação de intervenção médica foi quanto à sintomatologia da crise propriamente dita.

"Porque ele tava sem se alimentar, né? Tava sem se alimentar, tava sem poder até fazer suas necessidades e é tanto que ficou até através da sonda, ele ficou internado no hospital, só se alimentava pela sonda." (Leila, mãe de Samuel)

A manifestação de comportamentos bizarros, que podem estar relacionados aos pródromos, num primeiro momento, e/ou aos delírios e alucinações, quando da eclosão da crise, causou grande impacto sobre os familiares e sobre os próprios pacientes. A decisão por internar aquela pessoa pode se configurar difícil e até mesmo a última alternativa tentada; pelo estereótipo, o receio de ter seu parente "taxado" como louco e a própria dúvida de que esse procedimento fosse mesmo necessário. De modo concreto, a internação pode evitar situações de perigo tais como fuga, maus-tratos na rua ou mesmo tentativas de suicídio, resguardando a segurança física do paciente, como pode ser observado nos relatos a seguir.

"Eu tive umas fases... fiquei um tempo dentro do quarto, não saía do quarto, não saía da cama. Depois tive um tempo em que eu só queria ficar na rua, andando, andando, andando para todo lado." (Sandro)

\section{FATORES RELIGIOSOS}

A figura de Deus foi aludida pelos entrevistados como um recurso do qual se lançou mão durante a crise. Deus remetia à esperança e à resiliência que se deveria ter para atravessar esses períodos de sofrimento. Deus também aparece representando um dos pólos: bem e mal, certo e errado, entre ajuda profissional e a cura pela fé ou como conteúdo do delírio.

"Minha mãe, apesar dela, assim um pouco nervosa, também ajudou muito com as orações, que ela é muito temente a Deus, muito religiosa." (Lúcia) 
O contexto das manifestações aponta para a fraqueza da figura paterna, como acontece na estrutura psicótica. Porém não podemos afirmar categoricamente que esta circunstância faz parte das estruturas psicóticas, mas apenas de sua manifestação.

\section{MUDANÇAS DE VIDA}

Após a remissão da crise psicótica, pode-se perceber que modificações nas relaçôes familiares ou no comportamento do paciente ocorrem e quais benefícios ou perdas derivam dessa situação. Um dos grandes riscos decorrentes da crise é de colocar o "paciente identificado" num lugar cristalizado, de preocupação constante, favorecendo uma homeostase familiar disfuncional. A questão da autonomia, aqui representada pelo desemprego do paciente e preocupação da família, aponta para as crises relacionadas a transiçôes dos ciclos de vida (Carter \& McGoldrick, 1995), nas quais o sintoma simboliza o compromisso entre permanecer numa fase da vida ou seguir adiante.

"O que ele mudou é que ele gostava de sair, ele não sai mais. Agora ele não tá nem trabalhando, ele não pode nem fazer as despesas de casa, que ele tá desempregado." (Luzia)

É sabido que uma crise psicótica pode ou não evoluir para um quadro mais grave de esquizofrenia ou de outros transtornos. Contudo, ainda que isso não venha a acontecer, deve-se atentar para a eclosão da crise, uma vez que a mesma esconde uma casuística, ainda que desconhecida até então.

\section{CONSIDERAÇÕES FINAIS}

Quando propusemos o título Primeiras crises psicóticas e escolhemos o tempo de doze meses para definir estas crises, tinha-se em mente identificar o primeiro início ou o início mais precoce de uma crise. O critério de doze meses de história psiquiátrica se refere à intervenção precoce. Esse espaço de tempo seria um tempo mínimo para se caracterizar uma identificação precoce de sofrimento psíquico grave, afastando o fator de cronicidade dos casos, e estipulando um "afastamento de tempo" tal que não seria nem muito perto nem muito longe da crise.

Encontrou-se um recorte dos usuários dos serviços de saúde mental esclarecidos sobre as providências a serem tomadas quanto ao adoecimento, desde a busca por tratamento até o subsídio financeiro a que têm direito. $\mathrm{O}$ auxílio-doença concedido pelo INSS foi de grande importância para as famílias, principal- 
mente se levarmos em conta que os participantes, que são de renda baixa ou média, perderam seus empregos por conta do adoecimento.

$\mathrm{Na}$ análise do início do adoecimento, observou-se que os pacientes começaram apresentando mudança de comportamento sutil, caracterizada por uma sensação de medo que levou a um gradual afastamento social. Esse medo inicial, quando ainda não havia nenhum sintoma psicótico, pode ser interpretado como pródromo. Porém, no momento em que este se exacerba e se conecta a uma crença engendrada e fantasiosa, passa a ser visto como sintoma negativo decorrente, por exemplo, de delírio. Os delírios persecutórios foram os mais relatados, juntamente com as alucinaçôes auditivas. Quando da ocorrência de alucinação, os familiares atentaram para a gravidade da situação, até mesmo pelo aspecto mágico desse sintoma, que pôde ser logo identificado. Por outro lado, os delírios, por serem uma interpretação da realidade, ainda que absurda, são mais difíceis de serem identificados.

$\mathrm{O}$ relato de eventos concretos que foram associados ao desencadeamento da crise nos leva a pensar que as famílias estudadas não tinham qualquer relação com a eclosão da crise, sinalizando resistência e/ou desconhecimento sobre doença mental.

O perfil dos entrevistados aponta para uma representação cultural muito arraigada da figura feminina como cuidadora. Ainda que as questôes de gênero possam ser discutidas em múltiplos contextos, aqui elas se mostraram tradicionais. A simbolização do papel da mulher envolve o tema da maternagem que, em momentos de sofrimento, não necessariamente psíquico, torna-se mais explícita.

As mudanças na dinâmica familiar puderam ser percebidas no cuidado e na preocupação com o paciente. Para alguns entrevistados, a crise possibilitou que as responsabilidades da família fossem divididas entre vários membros, situação cujo benefício foi evidenciar a competência de alguns, delegando a eles maior poder de decisão. Por outro lado, também contribuiu para que os "mais responsáveis" amenizassem a sobrecarga de atribuiçóes sobre si. Houve quem relatasse acreditar que a situação de crise poderia gerar empatia entre o paciente e algum familiar com quem ele já tivesse desavenças antes da crise, o que não se confirmou.

Diante da complexidade e da relevância do tema abordado, é preciso que se desenvolvam outros estudos sobre as experiências de pessoas que passaram por situação de crises psicóticas, seja enquanto paciente, familiar ou profissional de saúde.

\section{REFERÊNCIAS BIBLIOGRÁFICAS}

Addington, J.; Collins, A.; McCleery, A. \& Addington, D. (2005). The role of family work in early psychosis. Schizophrenia Research, 79, 77-83. 
Bardin, L. (1988). Análise de conteúdo. São Paulo: Martins Fontes.

Barrowclough, C.; Tarrier, N. \& Johnston, M. (1996). Distress, expressed emotion and attributions in relatives of schizophrenia patients. Schizophrenia Bulletin, 22, 691-702.

Bech, P.; Malt, V. F.; Dencker, S. J. (1993). Scale for assessment of diagnosis and severity of mental disordres. Acta Psychiatica Scandinavica, 87 (372), 35-40.

Birchwood, M. (1992). Early intervention in psychosis: theoretical background and clinical strategies. British Journal of Clinical Psychology, 31, 257-278.

Burbach, F. R., \& Stanbridge, R. I. (1998). A family intervention in psychosis service integrating the systemic and family management approaches. Journal of Family Therapy, 20, 311-325.

Carter, B. \& McGoldrick, M. (1995). As mudanças no ciclo de vida familiar. Porto Alegre: Artes Médicas.

Costa, I. I. (2003). Da fala ao sofrimento psíquico grave: ensaios acerca da linguagem ordinária e a clínica familiar da esquizofrenia. Brasília: I. Izídio da Costa. . (no prelo). Família e psicose: uma proposta de intervenção precoce nas primeiras crises de sofrimento psíquico grave. Revista Brasileira de Enfermagem da USP.

DiTomasso, R. A. \& Kovnat, K. D. (1995). Pacientes da clínica geral. Em Dattilio \& Freeman (orgs). Estratégias cognitivo-comportamentais para intervenção em crises. Campinas: Editorial Psy.

Eaton, W. W.; Badawi, M. \& Melton, B. (1995). Prodroms and precursors: epidemiology data for primary prevention of disorders with slow onset. American Journal of Psychiatry, 152, 967-972.

Edwards, J.; Maude, D.; McGorry, P. D.; Harrigan, S. M. \& Cocks, J. T. (1989). Prolonged recovery in first-episode psychosis. British Journal of Psychiatry, 172 (supl. 33), 107116.

Franco, M. (2003). Análise de conteúdo. Brasília: Plano.

Freud, S. (1924). A perda da realidade na neurose e na psicose. Obras completas, ESB, v. XIX. Rio de Janeiro: Imago, 1976.

Hegenberg, M. (1996). Psicoterapia breve psicanalítica. TEMAS, 51, 38-50.

Leff, J. P.; Kupers, L.; Bertowitz, R. \& Strugeon, D. (1985). A controlled trial of social intervention in the families of schizophrenic patients. British Journal of Psychiatry, 141, 121-134.

Lines, E. (2003). An introduction to early psychosis intervention: some relevant findings and emerging practices. <http://www.cmha.ca/english/intervent/about.htm> Acessado em: $9 / 11 / 2006$.

Martens, J. \& Addington, J. (2001). The psychological well-being of family members in individuals with schizophrenia. Social Psychiatry and Psychiatric Epidemiology, 36, 128133. 
McGorry, P. D. \& Edwards, J. (2002). Intervenção precoce nas psicoses. São Paulo: JanssenCilag.

McGorry, P. D. \& Singh, B. (1995). Schizophrenia: risk and possibility of prevention. In Raphael, B. \& Burrows, G. D. (eds.). Handbook of Studies in Preventive Psychiatry (pp. 491-514). New York: Elsevier.

Miermont, J. \& Cols. (1994). Dicionário das terapias familiares. Teoria e prática. Porto Alegre: Artmed, 1994.

Minayo, M. C. S. (1994). Ciência, técnica e arte: o desafio da pesquisa social. In Minayo, M. C. S. (org.). Pesquisa social: teoria, método e criatividade. Petrópolis: Vozes.

Organização Mundial de Saúde (1993). Classificação de transtornos mentais e de comportamento da CID-10: Descriçôes clínicas e diretrizes diagnósticas. Porto Alegre: Artmed.

Power, P.; Elkins, K.; Adlard, S.; Curry, C.; McGorry, P. D. \& Harrigan, S. (1998). Analysis of the initial treatment phase in first-episode psychosis. British Journal of Psychiatry, 172 (33), 71-76.

Rhoades, H. \& Overall, J. (1988). The semi-structured BPRS interview and rating guide. Psychopharmacology Bulletin, 24 (1), 101-104.

Schene, A. H.; Tessler, R. C. \& Gamache, G. M. (1994). Instruments measuring family or caregiver burden in severe mental illness. Social Psychiatry and Psychiatric Epidemiology, 29, 228-240.

Schene, A. H.; van Wijngaarden, B. \& Koeter, M. W. J. (1998). Family caregiving in schizophrenia: domains and distress. Schizophrenia Bulletin, 24, 609-618.

Szmukler, G. I. (1996). From family "burden” to caregiving. Psychiatry Bulletin, 20, 449451.

Tavares, M. (2004). Crise psicológica. Manuscrito não publicado. Laboratório de Psicoterapia e Psicodiagnóstico, Instituto de Psicologia, Universidade de Brasília.

Recebido em 26 de abril de 2007 Aceito para publicação em 17 de abril de 2008 